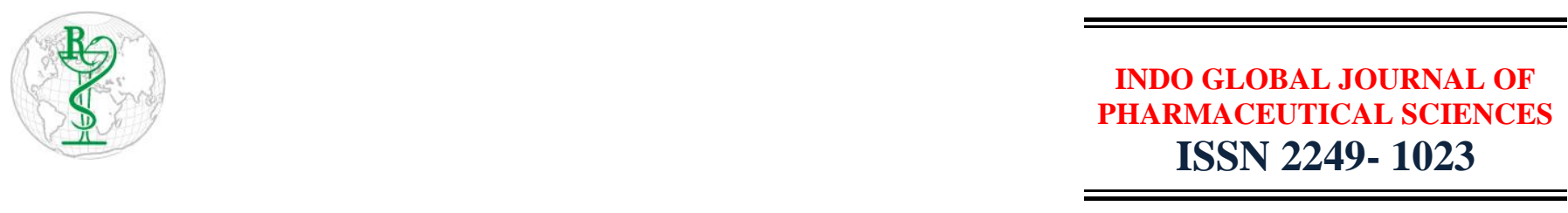

\title{
Neuroprotective Potential of Silymarin: Facts and Findings
}

\author{
Bhuban Subedi *, Shubham Kumar, Bimlesh Kumar, Indu Melkani, Sachin Kumar Singh \\ School of Pharmaceutical Sciences, Lovely Professional University, Phagwara, Punjab, India
}

Address for Correspondence: Bhuban Subedi, bimlesh.12474@lpu.co.in , bhubansubedi12@gmail.com

Received:

01.03.2019

Accepted:

25.03.2019

Keywords

Silymarin;

Antioxidant;

Neuroprotective.
ABSTRACT: Silymarin, a gold standard drug used to treat hepatic disorder is an extract obtained from the seed of the Milk thistle (Silybum marianum) belonging to the family of Asteraceae. Silybin A, silybin B, silychristin $\mathrm{A}$, silychristin $\mathrm{B}$, isosilybin $\mathrm{A}$, isosilybin $\mathrm{B}$, and silydianin are the major component associated with it. A C25 containing flavonoid, a potent antioxidant i.e. silymarin used to treat the cerebral ischemic haemorrage, and protective against cognitive deficits, brain damage and other CNS disorders. It is reported to have anticonvulsant, antidepressive, anticancer, anti-inflammation, antidiarrheal, antiulcer and vasodilator properties. It prevents conversion of Dopamine (DA) to DOPAC by inhibiting the dopamine oxidizing enzyme and monoamine Oxidase-B hence, leads to lesser degradation of DA and increased extracellular concentration of catecholamine neurotransmitter. Silymarin also inhibit the activation of NF-K $\beta$, P38MAPK to prevent inflammatory response, protect formation of $A \beta$ oligomerization with fibrilization to prevent oxidative stress and neuronal inflammation. Silymarin inhibit the activation of glycogen synthase kinase 3- $\beta$, production of P58, Apaf- $\alpha$ and caspase activation. It increases expression of BDNF which is essential for formation of neuronal synaptic connection for growth and learning. Hence, this presentation will focus on its clinical importance in a variety of neurodegenerative disorders and also offer improvements in its bioavailability to accurately validate its neuroprotective efficacy. (c) 2019 iGlobal Research and Publishing Foundation. All rights reserved.

Cite this article as: Subedi, B.; Kumar, S.; Kumar, B.; Melkani, I.; Singh, S.K. Neuroprotective potential of silymarin: facts and findings. Indo Global J. Pharm. Sci., 2019; 9(2Suppl.): 104. DOI: http://doi.org/10.35652/IGJPS.2019.92S02.

Indo Global Journal of Pharmaceutical Sciences( ISSN 2249 1023; CODEN- IGJPAI; NLM ID: 101610675) indexed and abstracted in CrossRef (DOI Enabling), UGC CARE Journal List, EMBASE(Elsevier), National Library of Medicine (NLM) Catalog, ResearchGate, Publons, CAS (ACS), Index Copernicus, Google Scholar and many more. For further details, visit http://iglobaljournal.com

This is a special issue as an outcome of 'RAPSCON-2019' sponsored by APTI and organized by Sri Sai College of Pharmacy, Manawala, Amritsar, Punjab, India. Relaxation offered in journal format. 